\title{
Blood groups and diabetes mellitus
}

\author{
A. L. MACAFEE \\ From the Department of Pathology, The Queen's University of Belfast
}

SYNOPSIS Eight hundred and sixty-five patients with diabetes mellitus showed ABO blood group frequencies closely similar to those expected from the controls. Six hundred and sixteen patients with diabetes mellitus showed frequencies of secretion and non-secretion of the $A B H(O)$ substances in the saliva closely similar to those expected from the controls. Four hundred and fifty-three patients with diabetes mellitus gave $\mathrm{MN}$ blood group frequencies very similar to those expected from the controls.

There are certain diseases which show strong evidence of association with the ABO blood groups, notably duodenal ulcer with blood group $O$ and carcinoma of the stomach with blood group A. However, examination of the literature produces conflicting results with regard to diabetes mellitus.

Results of a combined series from Lancashire, Cheshire, and Oxford (McConnell, Pyke, and Roberts, 1956) showed a significant excess of blood group A among male diabetics. On the other hand, in Copenhagen (Andersen and Lauritzen, 1960) an excess of blood group $\mathbf{O}$ was found in male diabetics. Results from Italy (Tedeschi and Cavazzuti, 1959) and Trinidad (Henry and Poon-King, 1961) both showed an increased frequency of blood group B among diabetics, but in Germany (Mähr, 1959) and in Glasgow (Craig and Wang, 1955) no significant difference was found between controls and patients with diabetes.

Recent evidence of the relationship between secretor status and diabetes mellitus came in a paper by Doll, Drane, and Newell (1961) in which, after examining the salivas of 102 diabetics, they concluded that the occurrence of diabetes mellitus was independent of the $\mathrm{ABH}(\mathrm{O})$ secretion.

Many of these workers have also studied the Rhesus and MN blood group systems but no associations have appeared.

The present investigation was therefore carried out in the light of these rather conflicting findings.

\section{MATERIALS}

The data were derived from 865 patients attending the diabetic out-patient clinic of the metabolic unit, the Royal Victoria Hospital, Belfast. There were 343 men and

Received for publication 7 June 1963.
522 women. All patients in this series had fully established diabetes mellitus: all patients were under treatment for the disease.

\section{CONTROLS}

In order to compare the $\mathrm{ABO}, \mathrm{MN}$, and secretor status of the patients with suitable controls, it was necessary for the patients and controls to be drawn from the same population. The ABO blood group distributions were, in fact, known for a large series $(11,327)$ of current blood donors normally resident in the County Borough of Belfast, consequently the patients studied were those normally resident in that area.

The MN blood group distribution for the population was not known and was therefore estimated in 202 people normally resident in Belfast. The medical and technical staff at the Belfast City Hospital laboratories, and antenatal patients attending out-patient clinics at the Royal Maternity Hospital, Belfast, for the first time made up the control series for this blood group distribution.

The distribution of the secretor status in the population was also not known and was therefore estimated in two independent series of persons normally resident in Belfast. The first was composed of 273 doctors, students, nurses, and technicians at the Royal Victoria Hospital, Belfast, and antenatal patients attending the out-patient clinics of the Royal Maternity Hospital, Belfast. The

\section{TABLE I}

DISTRIBUTION OF SECRETOR STATUS IN 475 CONTROLS BY INDIVIDUAL SERIES

Secretor Status Number of Controls

\begin{tabular}{|c|c|c|c|}
\hline & First Series & Second Series & Combined Series \\
\hline $\begin{array}{l}\text { Secretor } \\
\text { Non-secretor }\end{array}$ & $\begin{array}{l}172(63 \cdot 00)^{1} \\
101(37 \cdot 00)\end{array}$ & $\begin{array}{r}134(66 \cdot 34) \\
68(33.66)\end{array}$ & $\begin{array}{l}306(64.42) \\
169(35.58)\end{array}$ \\
\hline Total & $273(100 \cdot 0)$ & $202(100 \cdot 0)$ & $475(100 \cdot 0)$ \\
\hline
\end{tabular}


second series consisted of $\mathbf{2 0 2}$ doctors and technicians at the laboratories of the Belfast City Hospital and antenatal patients attending for the first time at the out-patient clinic of the Royal Maternity Hospital, Belfast. The two series were combined because there was no statistically significant difference (at $P=0.05$ ) between the two distributions (Table I), and were used in the subsequent analysis.

\section{METHODS}

A sample of blood was collected by venepuncture at the routine weekly diabetic clinic. The sample was divided, one for a blood sugar estimation and the other for blood grouping. For blood grouping the sample was allowed to clot in a clean dry $2 \mathrm{ml}$. tube and stored overnight at $4^{\circ} \mathrm{C}$. and tested the following day. The plate method was used for typing the $\mathrm{ABO}$ blood groups and the tube method was used in the estimation of the MN genotypes.

As the blood sample was being taken, the nature of the investigation was explained to the patient and a request made for a sample of saliva. The saliva was collected in a Mono container and the sample was then decanted into a small $2 \mathrm{ml}$. boiling tube. The tube was closed with nonabsorbent cotton wool and placed in a boiling water-bath for at least $\mathbf{1 0}$ minutes. The boiled saliva was stored overnight in a freezing chamber at less than $-4^{\circ} \mathrm{C}$. and tested the following day by an inhibition-agglutination reaction. All the tests were carried out with the assistance of the chief technician in the laboratories of the Northern Ireland Blood Transfusion Service. (The sera were provided by the Northern Ireland Blood Transfusion Service and the anti-H was prepared and extracted from the seeds of the Ulex europeus.) The $\chi^{2}$ test was used to estimate the probability of differences between distributions occurring by change and probabilities of less than $P=0.05$, as is conventional, indicate significant differences.

\section{RESULTS}

ABO BLOOD GROUPS In this series, 865 patients with diabetes mellitus were examined in relation to the ABO blood group distribution. In Table II the ABO distribution of the patients is compared with that expected from the 11,327 controls. There was no significant difference between the observed and expected distributions.

\section{TABLE II}

DISTRIBUTION OF 865 PATIENTS WITH DIABETES MELLITUS BY ABO BLOOD GROUP COMPARED WITH EXPECTED DISTRIBUTION IN CONTROLS

\begin{tabular}{cccc} 
Blood Group & Patients & Controls (\%) \\
& Total No. & \\
\hline A & $307(35.49 \%)$ & 37.01 \\
O & $446(51.56 \%)$ & 48.75 \\
B & $91(10.52 \%)$ & 10.85 \\
AB & $21(2.43 \%)$ & 3.39 \\
Total & $865(100.0 \%)$ & 100.0 \\
$x^{2}=4.379$ & d.f. $=3$ & $0.30>$ P $>0.20$.
\end{tabular}

When the data were subdivided by age of onset the disease, sex, and family history similar results. were obtained in all subgroups.

MN BLOOD GROUPS In this series, 453 patients wit? diabetes mellitus were examined in relation to the MN blood group distribution. In Table III it will be seen that there was no significant difference betwee the MN distribution of the patients and the appross priate controls.

When the data were subdivided by age of onset, sex, and family history similar results were obtained in all subgroups.

\section{TABLE III}

DISTRIBUTION OF 453 PATIENTS WITH DIABETES MELLITU BY THE MN BLOOD GROUP COMPARED WITH CORRESPONDINGO DISTRIBUTION IN 202 CONTROLS

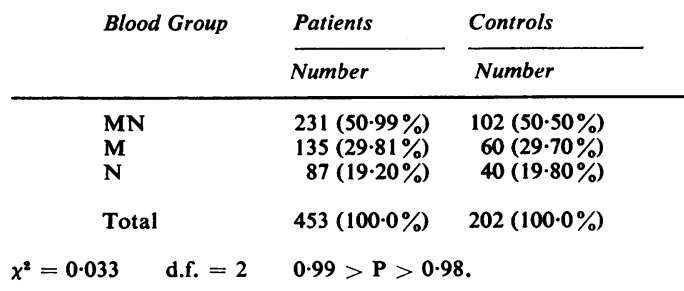

SECRETOR STATUS In this series, 616 patients wite diabetes mellitus were examined in relation $t \&$ secretion of the $\mathrm{ABH}(\mathrm{O})$ blood group substances if the saliva. In Table IV the secretor status distribution of the patients is compared with that of the controls and there was no significant difference between the two distributions.

Again, when the data were subdivided by age of onset, sex, and family history, similar results werẹ obtained in all subgroups.

\section{TABLE IV}

DISTRIBUTION OF 616 PATIENTS WITH DIABETES MELLITUS BV SECRETOR STATUS COMPARED WITH CORRESPONDING DISTRIBUTION IN 475 CONTROLS

\begin{tabular}{|c|c|c|}
\hline \multirow[t]{2}{*}{ Secretor Status } & Patients & Controls \\
\hline & Number & Number \\
\hline $\begin{array}{l}\text { Secretor } \\
\text { Non-secretor }\end{array}$ & $\begin{array}{l}387(62 \cdot 83 \%) \\
229(37 \cdot 17 \%)\end{array}$ & $\begin{array}{l}306(64.42 \%) \\
169(35.58 \%)\end{array}$ \\
\hline Total & $616(100 \cdot 0 \%)$ & $475(100 \cdot 0 \%)$ \\
\hline$x^{2}=0.295$ & $0.70>P>0.50$ & \\
\hline & DISCUSSION & \\
\hline
\end{tabular}

In order to combine and compare these data wit those of the literature the method devised by Wool (1955) was used. 
Many investigators have made estimates which suggest that the incidence of diabetes mellitus is relatively greater among persons of group A than among those of group $\mathrm{O}$; few, however, have found this relative excess to be significant (Table V).

\section{TABLE V}

RELATIVE INCIDENCE OF DIABETES MELLITUS IN PERSONS OF GROUP A COMPARED WITH INCIDENCE IN PERSONS OF GROUP O

$\begin{array}{llll}\text { Centre } & \begin{array}{l}\text { Total No. } \\ \text { of Patients }\end{array} & \begin{array}{l}\text { Relative Incidence } \\ \text { A:O }\end{array}\end{array} \quad \begin{aligned} & x^{2} \\ & \end{aligned}$

\begin{tabular}{|c|c|c|c|c|}
\hline $\begin{array}{l}1 \text { S.W. Lancashire } \\
2 \text { W. Cheshire } \\
3 \text { Oxford } \\
4 \text { Glasgow } \\
5 \text { Copenhagen } \\
6 \text { Germany } \\
7 \text { Trinidad } \\
8 \text { Modena } \\
9 \text { Belfast }\end{array}$ & $\begin{array}{r}634 \\
199 \\
500 \\
817 \\
992 \\
1,300 \\
355 \\
436 \\
865\end{array}$ & $\begin{array}{l}1 \cdot 12 \\
1 \cdot 19 \\
1 \cdot 11 \\
1 \cdot 18 \\
0 \cdot 83 \\
1 \cdot 07 \\
1 \cdot 12 \\
1 \cdot 28 \\
0.91\end{array}$ & $\begin{array}{l}1 \cdot 60 \\
1 \cdot 18 \\
1 \cdot 13 \\
4 \cdot 12 \\
7 \cdot 31 \\
1 \cdot 02 \\
0 \cdot 51 \\
4 \cdot 47 \\
1 \cdot 50\end{array}$ & $\begin{array}{l}0.30>\mathbf{P}>0.20 \\
0.30>\mathbf{P}>0.20 \\
0.30>\mathbf{P}>0.20 \\
0.05>\mathbf{P}>0.02 \\
0.01>\mathbf{P}>0.001 \\
0.50>\mathbf{P}>0.30 \\
0.70>\mathbf{P}>0.50 \\
0.05>\mathbf{P}>0.02 \\
0.30>\mathbf{P}>0.20\end{array}$ \\
\hline
\end{tabular}

Mean weighted relative incidence 1.05 .

$\chi^{2}\left\{\begin{array}{llrl}\text { Total } & \multicolumn{3}{c}{2 \cdot .84} \\ \text { Difference from unity } & \text { d.f. }=1 & 1 \cdot 35 & 0.30>P>0.20 \\ \text { Heterogeneity } & \text { d.f. }=8 & 21.49 & 0.02>P>0.01\end{array}\right.$

Source of material:

1-3 McConnell et al. (1956)

4 Craig and Wang (1955) (controls, Aird et al., 1960)

5 Andersen and Lauritzen (1960)

6 Măhr (1959)

7 Henry and Poon-King (1961)

8 Tedeschi and Cavazzuti (1959)

The significant findings are conflicting: in Glasgow and Modena the estimated incidence of diabetes mellitus in persons of blood group $\mathbf{A}$ is significantly greater than in those of blood group $\mathrm{O}$, but in Copenhagen the estimated incidence in persons of blood group $O$ is significantly greater than those of blood group A. There is evidence of significant heterogeneity between areas and for this reason the data from different areas cannot be pooled. The results are still conflicting and the present series tends to add to this conflict.

This investigation is the third in which the MN blood group distribution has been examined in diabetes mellitus; 3,139 patients were examined in Oxford (McConnell et al., 1956), Iowa (Buckwalter and Tweed, 1962), and Belfast, and in all centres the $\mathrm{MN}$ distribution of the patients closely resembled the MN distribution of the controls.

This investigation is the second in which the secretor status has been examined and it supports the finding of Doll et al. (1961) who concluded that the occurrence of diabetes mellitus was independent of the $\mathrm{ABH}(\mathrm{O})$ secretion.

It is appreciated that these results are based on essentially factual observations but epidemiological studies of this kind are, in the words of Aird and Roberts (1962), 'the beginning not the end of research, they direct attention to what might profitably be looked for'.

I wish to acknowledge the help and encouragement of Professor J. H. Biggart, who initially suggested the investigation of this problem. I am very grateful to Professor E. A. Cheeseman for his advice and assistance in the preparation of this paper. Dr. D. A. D. Montgomery and Dr. J. Weaver permitted me to examine their patients. Dr. M. C. Huth provided the ABO blood group control data and gave me access to her laboratories. I wish to thank Mr. T. Wilson for valuable technical assistance. I am grateful also to Mr. J. D. Merritt, Mrs. J. McCabe, Sister M. Russell, and Sister E. Good who willingly assisted me throughout this work, and to Miss $M$. Weller who prepared the typescript.

\section{REFERENCES}

Aird, I., Lee, D. R., and Roberts, J. A. Fraser (1960). Brit. med. J., 1, 1163.

- and Roberts, J. A. Fraser (1962). Lancet, 1, 968.

Andersen, J., and Lauritzen, E. (1960). Diabetes, 9, 20.

Buckwalter, J. A., and Tweed, G. V. (1962). J. Amer. med. Ass., 179, 479.

Craig, J., and Wang, I. (1955). Glasg. med. J., 36, 261.

Doll, R., Drane, H., and Newell, A. C. (1961). Gut, 2, 352.

Henry, M. U., and Poon-King, T. (1961). W. Indian med. J., 10, 156. McConnell, R. B., Pyke, D. A., and Roberts, J. A. Fraser (1956). Brit. med. J., 1, 772 .

Mähr, G. von (1959). Wien. klin. Wschr., 71, 536.

Tedeschi, G., and Cavazzuti, F. (1959). Progr. med. (Napoli), $15,76$. Woolf, B. (1955). Ann. hum. Genet., 19, 251. 